\title{
Validation and application of a chromatographic method for evaluation of commercial vegetable oils possibly adulterated
}

\author{
Validação e aplicação de um método cromatográfico para avaliação de óleos vegetais comerciais \\ possivelmente adulterados
}

\author{
Katarynna Santos Araújo ${ }^{1}$, Mariana Oliveira Barbosa ${ }^{2}$, Carolina Barbosa Malafaia ${ }^{3}$ \\ e Daniella Carla Napoleão ${ }^{4}$ \\ 1,2,3 Centro de Tecnologias Estratégicas do Nordeste, PE, Brasil \\ katarynna.araujo@gmail.com; mariana.olbarbosa@gmail.com; carol08malafaia@hotmail.com \\ ${ }^{4}$ Departamento de Engenharia Química, Universidade Federal de Pernambuco, PE, Brasil.
}

\author{
danicarlan@gmail.com
}

\begin{abstract}
A method of separation, identification and quantification of fatty acid methyl esters (FAMEs) was developed by gas chromatography with flame ionization detector (GC-FID) using a basic transesterification. In this sense, there were analyzed FAMEs in commercial samples of vegetable oils from soybean and olive oil. The referred method was linear ( $r>0.99)$, accurate and precise for palmitic (C16:0), linoleic (C18:2), oleic (C18:2), linolenic (C18:3) and stearic (C18:0) acids. The limits of detection (LOD) and quantification (LOQ) were from 0.03 to 0.31 and 0.08 to 0.94 $m g . m L^{-1}$ for the five fatty acids, respectively. The results demonstrated that the unsaturated fatty acids were the most abundant for the two samples, being the oleic acid (C18:1) the major in three brands of olive oil (D, E and F), and the linoleic acid (C18:2) the most abundant in soybean oil and the other brands of olive oil ( $G, H$ and I), suggesting a possible adulteration in these brands. The proposed method could be considered a tool for the investigation of adulteration in commercial vegetable oils for guaranteed reliability in the results to be comparable with correlated legislations.
\end{abstract}

Keywords: adulteration; GC-FID; olive oil; soybean oil; unsaturated fatty acids

\section{Resumo}

Um método de separação, identificação e quantificação de metil ésteres de ácidos graxos (FAMEs) foi desenvolvido por cromatografia gasosa com detector de ionização de chama (GC-FID) usando uma transesterificação básica. Nesse sentido, foram analisados os FAMEs em amostras comerciais de óleos vegetais de soja e azeite de oliva. O método referido foi linear ( $r>0,99)$, acurado e preciso para os ácidos palmítico (C16: 0), linoléico (C18: 2), oleico (C18: 2), linolênico (C18: 3) e esteárico (C18: 0). Os limites de detecção (LOD) e quantificação (LOQ) foram de 0,03 a 0,31 e 0,08 a 0,94 mg. $\mathrm{mL}^{-1}$ para os cinco ácidos graxos, respectivamente. Os resultados demonstraram que os ácidos graxos insaturados foram os mais abundantes para as duas amostras, sendo o ácido oleico (C18: 1) o principal em três marcas de azeite (D, E e F) e o ácido linoléico (C18: 2 ) a mais abundante em óleo de soja e as outras marcas de azeite $(G, H$ e I), sugerindo uma possível adulteração nessas marcas. O método proposto poderia ser considerado uma ferramenta para a investigação de adulteração em óleos vegetais comerciais, garantindo confiabilidade nos resultados para ser comparável com as legislações correlacionadas.

Palavras-chave: Adulteração; CG-DIC; Azeite de oliva; Óleo de soja; Ácidos graxos insaturados 


\section{Introduction}

Vegetable oils are water-insoluble substances basically formed by esterified fatty acids and glycerol, compounding the triglycerides (Salimon et al. 2017). They are extracted from oleaginous plants, whose composition have a higher proportion of unsaturated fatty acids, characteristic directly related to its liquid state at room temperature (approximately $25^{\circ} \mathrm{C}$ ) (Seppänen-Laakso et al., 2002). Fatty acids play a key role in human nutrition due to its implication in enzymatic reactions, nerve impulse transmission, memory storage and synthesis of hormones, in addition to its action as fat-soluble vitamins carriers (Petrović et al., 2010).

Soybean oil is the second most consumed vegetable oil in the world market, and represents more than half of all oil used in food products in the Brazilian market (Siqueira et al. 2016). The olive oil is widely appreciated due to its taste and nutritional value (Nunes et al. 2013; Jabeur et al. 2016); it is also important to highlight its production in the world food industry and the high consumption worldwide and in the Brazilian market (Siqueira et al. 2016). In view of this, characterization methods are required to assess the veracity or adulteration of vegetable oils, since adulteration in commercial products is a major market problem and must be investigated to ensure both safety and law consumers (Mendes et al. 2015; Sun et al. 2015; Jabeur et al. 2016).

Nowadays, the gas chromatography technique associated to the mass spectrometer (MS) or the flame ionization detector (FID) is the most used to determine the composition of fatty acids in simple or complex matrices of vegetable oils (Gómez-Coca et al. 2016; Yurchenko et al. 2016; Bravi et al. 2017). This technique is able to perform the separation of fatty acids, since they present a volatile nature, which allows the methylation of triglycerides and consequently their separation in fatty acid methyl esters (FAMEs) (Delmonte et al. 2009).

However, proceeding identification and quantification of fatty acids singly is not enough; it is essential the reliability of the technique. The validation of a chromatographic method is one of the basic elements in quality systems ensuring the efficiency and suitability of the for the intended purpose (ANVISA, 2017). For this, different parameters including linearity, precision, accuracy, limit of detection and quantification, among others, should be studied (ABNT, 2005; ANVISA, 2017; Brito, 2003).The scientific literature reports several works using validation of fatty acids for various purposes, for example in dairy industry, brewing, baking, commercial samples of margarine, palm oil and others (Simionato et al. 2010; Omar and Salimon 2013; Godswill et al. 2014; Bravi et al. 2017).

Due to the implementation of new regulations that require the data about the composition of fatty acids in labels over several countries (Brandt et al. 2009), the need for rapid, cheap, efficient, precise and accurate methods is increasing in the way to determine the content of the marketed products in order to guarantee the reliably of the information on the labels.

The objective of this work was the validation of a simple methodology for obtaining and analyze by gas chromatography the fatty acid methyl esters (FAMEs), verifying its efficiency in real samples of oils commercialized in the state of Pernambuco, Brazil.

\section{Materials and Methods}

\subsection{Standards, reagents and samples}

There were selected five fatty acid patterns of different carbon chain sizes in the amount of unsaturations and their respective positions in the molecules: palmitic (C16:0), stearic (C18:0), linoleic (C18:1), oleic (C18:2) and linolenic acid (C18:3). All standards were purchased from Sigma-Aldrich (Germany) with a purity of at least $99 \%$. All solvents and reagents were of analytical grade: potassium hydroxide (KOH, Vetec,> 99\%, Brazil), methanol (Alphatec,> 99\%, Brazil), and $\mathrm{n}$-hexane (Alphatec, $>99 \%$, Brazil).

Commercial samples of soybean oil and olive oil were selected according to the most popular supermarket brands in Pernambuco/Brazil. Based on the diversity of commercial brands of these products, 3 brands of soybean oil and 6 brands of olive oil were chosen for analysis and validation by the 
proposed method. Each tag was analyzed from three different samples. Samples were analyzed to determine the lipid profile and the concentration of fatty acids in each of them. Samples were separated into aliquots, stored in amber flasks, and finally named according to the type: soybean oil (A, B and C) and olive oil (D, E, F, G, H and I).

\subsection{Standards preparation}

A stock solution in maximum concentration was prepared from the mixture of standards containing saturated, monounsaturated and polyunsaturated fatty acids. From this solution, eight analytical curves with eight concentration levels were prepared by dilutions with the n-hexane solvent (Table 1). All solutions were stored at $-20^{\circ} \mathrm{C}$ until chromatographic analysis.

\subsection{FAMEs preparation}

FAMEs were prepared from $40 \mu \mathrm{L}$ of commercial vegetable oils, adding $500 \mu \mathrm{L}$ of $\mathrm{KOH}$ in 0.5 mol. $\mathrm{L}^{-1}$ methanol, and stirred in vortex for $2 \mathrm{~min}$. After that, $2 \mathrm{~mL}$ of $\mathrm{n}$-hexane P.A. were added at the same stirring conditions. After complete separation of the phases, the samples were centrifuged at 4500 $\mathrm{rpm}$ for $6 \mathrm{~min}$ at $25{ }^{\circ} \mathrm{C}$ and the supernatant was collected and filtered using $0.22 \mu \mathrm{m}$ PTFE (polytetrafluoroethylene) membrane. FAMEs aliquots were conditioned in vials until analysis GC.

\subsection{Analysis of FAMEs by GC}

FAMEs samples were injected in triplicate into GC-FID (Agilent Technologies, 7890A) for separation, identification and quantification of the analytes. The analysis was performed by injecting $1 \mu \mathrm{L}$ in 1: 100 split mode into a DB5-MS capillary column $(30 \mathrm{~m}, 0.25 \mathrm{~mm}$ di, $0.25 \mu \mathrm{m}$ film thickness of $5 \%$ phenyl and 95\% dimethyl polysiloxane, Agilent Technologies, USA). Injection and detection temperatures were $300{ }^{\circ} \mathrm{C}$, while oven temperature take into account an isotherm of $210{ }^{\circ} \mathrm{C}$ for $15 \mathrm{~min}$. Helium was used as drag gas with flow of $1 \mathrm{~mL} \cdot \mathrm{min}^{-1}$.

\subsection{Validation procedure}

2.5.1. Identification and calibration

Standard solutions and samples were prepared under the same conditions for injection in the chromatographic system. Samples of the FAMEs from soybean oil and olive oil were identified by comparison of the retention time (Rt) between them and the analytical standards. The commercial oil samples were quantified by analytical curves prepared in terms of $\mathrm{mg}^{\mathrm{mL}} \mathrm{mL}^{-1}$ in the concentration range described previously (Table 1), using the analytical curves of the FAMEs as a tool. The lipid profile of the samples was determined by area normalization.

\subsubsection{FAMEs validation}

The validation of the methodology was performed based on the standards required by ANVISA Agência Nacional de Vigilância Sanitária and INMETRO - Instituto Nacional de Metrologia. The parameters adopted were the following: selectivity, linearity, precision, accuracy, limit of detection (LOD) and limit of quantification (LOQ) (ANVISA, 2017; INMETRO, 2010).

The linearity was determined by the correlation coefficient (r) obtained from the analytical curves of the fatty acids. The sensitivity of the detector was determined by the slope values of the equations generated by each analyte.

Precision was measured by the coefficient of variation (CV\%) based on Equation 1 . The LOD and LOQ were verified through the results obtained for the analytical curves based on the estimate of the standard deviation (s) and slope of the curve (S), according to Equations 2 and 3.

Accuracy was defined by the sample fortification method in which three levels of concentration were prepared. These samples were analyzed in triplicate and the recovery calculation was performed according to Equation 4. Please see Table 1 for Equations 1 to 4. 
Table 1 - Equations used to calculate the validation parameters

\begin{tabular}{lcl}
\hline Validation parameters & Equations & Citation \\
\hline Precision & $C V \%=\frac{s}{x} * 100$ & Equation 1 \\
Limit of detection & $L O D=3.3 * \frac{s}{S}$ & Equation 2 \\
Limit of quantification & $L O Q=10 * \frac{s}{S}$ & Equation 3 \\
Accuracy & $R(\%)=\frac{\left(C_{1}-C_{2}\right)}{C_{3}} * 100$ & Equation 4 \\
\hline
\end{tabular}

Where $\mathrm{s}$ is the absolut standard deviation, $\mathrm{x}$ is the arithmetic average, $\mathrm{S}$ is the curve slope, $\mathrm{C}_{1}$ is the concentration in the sample with standard addition, $\mathrm{C}_{2}$ is the concentration in the sample without standard addition, and $\mathrm{C}_{3}$ is the concentration of the added standard.

\subsection{Statistical treatment}

To ensure the reliability of the data, results of the analytical curves were submitted to the Grubb's test at $95 \%$ confidence level (Grubbs and Beck 2017). The results of commercial vegetable oil samples were analyzed using the analysis of variance (ANOVA One-way) with 5\% significance and Tukey's test using Statistica software version 8.0 (Statsoft, Inc). Calculations of means, standard deviations and percentages were performed by Microsoft Excel software (Professional Edition 2007; Microsoft Coorporation, Redmond, WA). All tests were performed in triplicate.

\section{Results and discussion}

\subsection{Qualitative analysis of the analysis method of FAMEs by GC-FID}

GC-FID analysis identified the acids C16:0, C18:0, C18:1, C18:2 and C18:3 through the retention time (Table 2). The chromatographic methodology showed to be selective for the analysed fatty acids, since it guaranteed an efficient separation in a $15 \mathrm{~min}$ chromatographic run (Figure 1). The chromatogram showed peaks with a similar behavior when compared to the ones from soybean oils already reported by the scientific literature (Seppänen-Laakso et al. 2002; Dubois et al. 2007; Dhakal et al. 2009a).

Table 2 -Equations of the analytical curves and their correlation coefficients. Concentration in $\mathrm{mg} \cdot \mathrm{mL}^{-1}$

\begin{tabular}{cccccc}
\hline Fatty acid & Formula & Rt (min) & Curve concentration range & Line's equation $^{\mathrm{a}}$ & $\mathbf{r}$ \\
\hline Palmitic acid & $\mathrm{C} 16: 0$ & 7.443 & 0.22 a 6.92 & $\mathrm{y}=8.6005 \mathrm{x}+0.3184$ & 0.9997 \\
Stearic acid & $\mathrm{C} 18: 0$ & 12.997 & 0.08 a 2.53 & $\mathrm{y}=9.4435 \mathrm{x}-0.3701$ & 0.9973 \\
Oleic acid & $\mathrm{C} 18: 1$ & 12.152 & 0.56 a 17.77 & $\mathrm{y}=8.5291 \mathrm{x}+1.1072$ & 0.9996 \\
Linoleic acid & $\mathrm{C} 18: 2$ & 11.946 & 0.98 a 31.33 & $\mathrm{y}=8.5316 \mathrm{x}+1.7583$ & 0.9998 \\
Linolenic acid & $\mathrm{C} 18: 3$ & 12.290 & 0.09 a 1.46 & $\mathrm{y}=11.74 \mathrm{x}-0.5286$ & 0.9985 \\
\hline
\end{tabular}

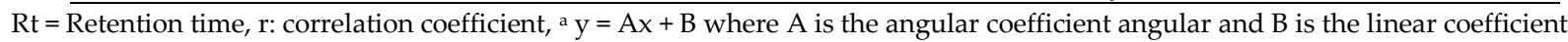

\subsection{Statistical analysis of analytical curves}

Table 3 shows the results of the mean areas, standard deviations, as well as the values of $\mathrm{G}<\mathrm{e}$ G> obtained for the Grubb's test of the analyzed fatty acids. The chromatogram areas obtained for each concentration level of the eight analytical curves obeyed the value defined by the Grubb's test, thus excluding the presence of gross errors. All values obtained from the results of the areas were accepted with $95 \%$ confidence for a minimum of seven levels of concentration (Barros Neto et al. 2002). 
Table 3 - Values of the Grubb's test for palmitic (C16:0), stearic (C18:0), oleic (C18:1), linoleic (C18:2), and linolenic (C18:3) acids. Concentration in $\mathrm{mg} \cdot \mathrm{mL}^{-1}$

\begin{tabular}{|c|c|c|c|c|c|c|c|c|c|}
\hline \multicolumn{5}{|c|}{ C16:0 } & \multicolumn{5}{|c|}{ C18:2 } \\
\hline \multirow{3}{*}{ 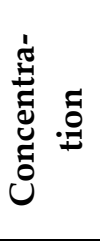 } & \multirow{3}{*}{ 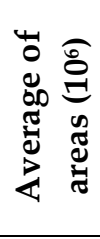 } & \multirow{3}{*}{ 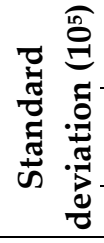 } & \multirow{2}{*}{\multicolumn{2}{|c|}{$\begin{array}{c}\text { Grubb's Test } \\
95 \% \\
\text { confidence }(*)\end{array}$}} & \multirow{3}{*}{ 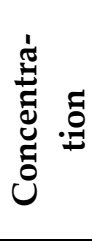 } & \multirow{3}{*}{ 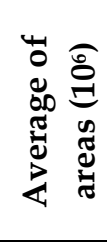 } & \multirow{3}{*}{ 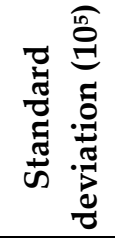 } & \multirow{2}{*}{\multicolumn{2}{|c|}{$\begin{array}{c}\text { Grubb's Test } \\
95 \% \\
\text { confidence }(*)\end{array}$}} \\
\hline & & & & & & & & & \\
\hline & & & $\mathrm{G}<$ & $\mathrm{G}>$ & & & & $\mathrm{G}<$ & $G>$ \\
\hline 0.22 & 0.20 & 0.18 & 0.8268 & 0.3998 & 0.98 & 0.93 & 0.80 & 0.8070 & 0.4392 \\
\hline 0.43 & 0.40 & 0.37 & 0.7164 & 0.6981 & 1.96 & 1.83 & 1.59 & 0.7104 & 0.7767 \\
\hline 0.87 & 0.78 & 0.74 & 0.8068 & 0.9285 & 3.92 & 3.54 & 3.21 & 0.7789 & 0.9304 \\
\hline 1.73 & 1.54 & 1.54 & 0.8113 & 0.9557 & 7.83 & 6.91 & 6.62 & 0.8545 & 10.576 \\
\hline 2.31 & 2.01 & 0.69 & 19.597 & 11.849 & 10.44 & 9.02 & 3.09 & 20.174 & 10.628 \\
\hline 3.46 & 1.54 & 1.54 & 0.6786 & 10.503 & 15.66 & 13.54 & 12.43 & 0.7862 & 0.9478 \\
\hline 5.19 & 4.56 & 4.38 & 12.550 & 13.716 & 23.50 & 20.51 & 19.76 & 11.921 & 13.909 \\
\hline 6.91 & 5.94 & 5.31 & 11.255 & 0.7301 & 31.33 & 26.69 & 23.12 & 12.302 & 0.6746 \\
\hline
\end{tabular}

\begin{tabular}{|c|c|c|c|c|}
\hline \multicolumn{5}{|c|}{ C18:1 } \\
\hline \multirow{3}{*}{ 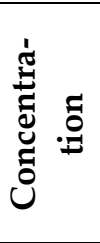 } & \multirow{3}{*}{ 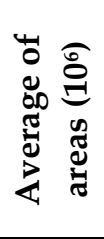 } & \multirow{3}{*}{ 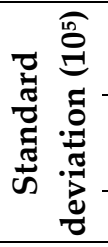 } & \multirow{2}{*}{\multicolumn{2}{|c|}{$\begin{array}{c}\text { Grubb's Test } \\
95 \% \\
\text { confidence }\left(^{*}\right)\end{array}$}} \\
\hline & & & & \\
\hline & & & $\mathrm{G}<$ & G> \\
\hline 0.56 & 0.52 & 0.50 & 0.8464 & 0.4910 \\
\hline 1.11 & 1.04 & 0.95 & 0.7070 & 0.7410 \\
\hline 2.22 & 2.01 & 1.93 & 0.7723 & 0.9011 \\
\hline 4.44 & 3.94 & 4.00 & 0.7997 & 10.317 \\
\hline 5.92 & 5.15 & 1.85 & 19.941 & 0.9593 \\
\hline 8.88 & 7.69 & 7.66 & 0.7456 & 0.9693 \\
\hline 13.32 & 11.67 & 11.48 & 12.048 & 13.333 \\
\hline 17.77 & 15.11 & 13.18 & 12.172 & 0.6907 \\
\hline
\end{tabular}

\begin{tabular}{|c|c|c|c|c|c|c|c|c|c|}
\hline \multicolumn{5}{|c|}{ C18:3 } & \multicolumn{5}{|c|}{ C18:0 } \\
\hline \multirow{3}{*}{ 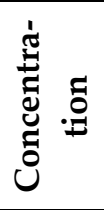 } & \multirow{3}{*}{ 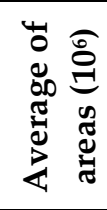 } & \multirow{3}{*}{ 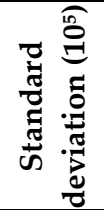 } & \multirow{2}{*}{\multicolumn{2}{|c|}{$\begin{array}{c}\text { Grubb's Test } \\
95 \% \\
\left.\text { confidence }{ }^{*}\right)\end{array}$}} & \multirow{3}{*}{ 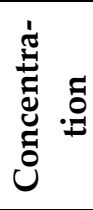 } & \multirow{3}{*}{ 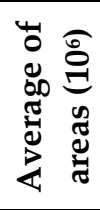 } & \multirow{3}{*}{ 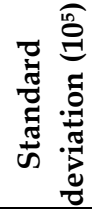 } & \multirow{2}{*}{\multicolumn{2}{|c|}{$\begin{array}{c}\text { Grubb's Test } \\
95 \% \\
\text { confidence }(*)\end{array}$}} \\
\hline & & & & & & & & & \\
\hline & & & $\mathrm{G}<$ & $\mathrm{G}>$ & & & & $\mathrm{G}<$ & G> \\
\hline 0.09 & 0.79 & 0.78 & 0.7132 & 0.4684 & 0.08 & 0.71 & 0.72 & 0.9116 & 0.3780 \\
\hline 0.18 & 1.60 & 1.67 & 0.6739 & 0.9617 & 0.16 & 1.42 & 1.41 & 0.6723 & 0.6676 \\
\hline 0.36 & 3.61 & 4.83 & 10.343 & 11.045 & 0.32 & 2.78 & 2.91 & 0.6448 & 0.7865 \\
\hline 0.49 & 4.85 & 4.76 & 17.531 & 12.945 & 0.63 & 5.55 & 5.93 & 0.8176 & 10.578 \\
\hline 0.73 & 8.00 & 10.70 & 10.149 & 0.9189 & 0.84 & 7.31 & 2.65 & 20.132 & 12.337 \\
\hline 1.09 & 12.55 & 17.36 & 15.625 & 10.823 & 1.27 & 11.16 & 13.73 & 0.7565 & 12.023 \\
\hline 1.46 & 16.54 & 17.55 & 0.9328 & 0.8515 & 1.90 & 17.97 & 27.36 & 11.987 & 0.7190 \\
\hline- & - & - & - & - & 2.53 & 23.71 & 35.52 & 10.234 & 0.9139 \\
\hline
\end{tabular}




\subsection{Linearity and sensitivity}

Linearity is the parameter that evaluates the proportionality between the signal obtained from the analyte and its concentration in the sample, in a determined operating range, through the determination of the correlation coefficient (Tiwari and Tiwari 2010). The fatty acids analytical curves showed to be linear with $\mathrm{r}$ ranging from 0.9973 (C18:0) to 0.9998 (C18:2) for the studied concentration ranges (Table 3). Therefore, the method proposed in this study was linear for all the analysed fatty acids in compliance with INMETRO and ANVISA regulation (ANVISA, 2017; INMETRO, 2010). The linearity was also shown to be higher for all the studied fatty acids when compared to other validated methodologies (Omar and Salimon 2013; Wirasnita et al. 2013; Salimon et al. 2017).

The sensitivity measures the ability of the method to identify similar analytes within a matrix and separate them (Slemr et al. 2004). The values of the slopes of the analytical curves were very similar (mean value of 9.3688), demonstrating a similar behaviour of the detector through the analytes, thus confirming the sensitivity of the proposed method.

\subsection{Precision}

Precision measures the dispersion of the data and evaluates the proximity of the results obtained from a sample submitted to series of, being able to be determined by the coefficient of variation (CV\%) (Barros Neto et al. 2002). A method is considered precise when CV\% values are at most $20 \%$ for trace or complex samples (Ribani et al. 2004).

C18:2 was the fatty acid with lower dispersion between concentration levels, varying from $3.4 \%$ to 9.6\%, while C18:0 presented the higher CV\% (15.2\%) (Table 4). Therefore, the proposed method was precise for the five analytes in the experimental interval since it presented all the $\mathrm{CV} \%$ results lower than 20\% (Jiang et al. 2015; Yurchenko et al. 2016).

Table 4 - Coefficients of variance determining the accuracy of the method for fatty acids

\begin{tabular}{cccccc}
\hline Points of the analytical curves* & \multicolumn{7}{c}{ CV (\%) } \\
\hline & C16:0 & C18:0 & C18:1 & C18:2 & C18:3 \\
\hline $\mathbf{1}$ & 9.1 & 10.2 & 9.5 & 8.6 & - \\
$\mathbf{2}$ & 9.3 & 10.0 & 9.2 & 8.7 & 10.6 \\
$\mathbf{3}$ & 9.5 & 10.5 & 9.6 & 9.1 & 13.8 \\
$\mathbf{4}$ & 10.0 & 10.7 & 10.2 & 9.6 & 13.4 \\
$\mathbf{5}$ & 9.7 & 12.3 & 10.0 & 9.2 & 9.8 \\
$\mathbf{6}$ & 3.4 & 3.6 & 3.6 & 3.4 & 13.4 \\
$\mathbf{7}$ & 9.6 & 15.2 & 9.8 & 9.6 & 10.4 \\
$\mathbf{8}$ & 8.9 & 15.0 & 8.7 & 8.7 & 9.9 \\
\hline
\end{tabular}

$\left.{ }^{*}\right)$ The numbering from 1 to 8 refers to the lowest concentrations (1) to the highest (8) of the analytical curves.

\subsection{Accuracy}

The accuracy indicates the proximity of the obtained results in relation to their true value, that is, it measures the agreement of the method. In what concerns the accuracy of an analytical method, it is necessary that its recovery rate ( $\mathrm{R} \%$ ) vary between 70 and $120 \%$ of the reference value (Ribani et al. 2004; Faria et al. 2007).

The calculated recovery rate values for the five fatty acids are shown in Table $5 . \mathrm{R} \%$ ranged from $84.0 \%$ to $114.7 \%$ of all concentrations and all analytes. C18:2 and C18:0 acids had the lowest percentage deviations in this parameter $(84.0 \%$ and $91.3 \%$, respectively), whereas C18:3 had the highest $\mathrm{R} \%$ values $(114,7 \%)$, results that are in agreement with the scientific literature for the C16:0, C18:0, C18:1, C18:2 and C18:3 acids (Simionato et al. 2010; Omar and Salimon 2013; Yurchenko et al. 2016; Salimon et al. 2017). The closer to $100 \%$, the more exact the method is considered, therefore, as all analytes have been demonstrated with values within the limit quoted in the literature, it is possible to confirm that the proposed method presents reliable results. 
Table 5 - Percent recovery values for fatty acids. Concentration in $\mathrm{mg} \cdot \mathrm{mL}^{-1}$

\begin{tabular}{lcccccc}
\hline \multirow{2}{*}{ Parameters } & \multirow{2}{*}{ Concentration } & \multicolumn{5}{c}{ Fatty acids } \\
\cline { 3 - 7 } & & $\mathbf{C 1 6 : 0}$ & $\mathbf{C 1 8 : 0}$ & $\mathbf{C 1 8 : 1}$ & $\mathbf{C 1 8 : 2}$ & C18:3 \\
\hline Accuracy & $7.5+15$ & $95.3 \pm 1.3$ & $95.9 \pm 1.4$ & $94.4 \pm 0.9$ & $94.3 \pm 0.9$ & $103.8 \pm 0.8$ \\
(recovery & $15+15$ & $112.2 \pm 3.5$ & $109.3 \pm 3.2$ & $111.9 \pm 3.6$ & $111.5 \pm 3.5$ & $114.7 \pm 3.3$ \\
percentage R\%) & $30+15$ & $96.2 \pm 2.6$ & $91.3 \pm 2.2$ & $95.0 \pm 3.1$ & $84.0 \pm 15.3$ & $112.1 \pm 4.5$ \\
LOD & - & 0.07 & 0.03 & 0.19 & 0.31 & 0.03 \\
LOQ & - & 0.21 & 0.08 & 0.58 & 0.94 & 0.08 \\
\hline
\end{tabular}

\subsection{Limit of detection and quantification}

Limit of detectation (LOD) is defined as the least amount of an analyte perceivable to be detected in a sample, whereas the limit of quantification (LOQ) is the least amount of an analyte that can be reliable quantified with parameters such as precision and accuracy (ANVISA, 2017; INMETRO, 2010). The LOD and LOQ values of the fatty acids obtained in this study are shown in Table 5.

The values for the five fatty acids ranged from 0.03 to $0.31 \mathrm{mg} \cdot \mathrm{mL}^{-1}$ for LOD, and 0.08 to 0.94 mg.mL-1 for LOQ. In what concerns LOQ values, they were higher than LOD because high concentrations are required for quantification than for detection. C18:0 and C18:3 had the lowest values of LOD (0.03 mg.mL-1) and LOQ $\left(0.08 \mathrm{mg} \cdot \mathrm{mL}^{-1}\right)$ among the other analytes, probably due to its lowest concentrations in the prepared standards mixture. Likewise, C18:1 and C18:2 presented the highest values of LOD (0.19 and $0.31 \mathrm{mg} \cdot \mathrm{mL}^{-1}$, respectively) and LOQ (0.58 and $0.94 \mathrm{mg} \cdot \mathrm{mL}^{-1}$, respectively) because their fatty acids were more concentrated in the prepared standard. The other fatty acids presented intermediate values of LOD and LOQ. Therefore, these values comprise the minimum margins for an efficient quantification of fatty acids in samples of commercial vegetable oils (ANVISA, 2017; INMETRO, 2010).

\subsection{Analysis of commercial vegetable oils}

Brazilian and international legislation for quality control of vegetable oils determines the presentation of fatty acids in terms of percentage (MAPA, 2012, 2006). Therefore, the lipid profile for samples of soybean oil and olive oil were determined and expressed in Table 6.

Table 6 - Percentage composition of fatty acids of commercial oil' samples

\begin{tabular}{lccccc}
\hline \multirow{2}{*}{ Samples } & \multicolumn{7}{c}{ Percentage of fatty acids (\%) } \\
\cline { 2 - 6 } & C16:0 0 & C18:0 & C18:1 & C18:2 & C18:3 \\
\hline A & $11.3 \pm 0.3 \mathrm{Ca}$ & $3.8 \pm 0.5 \mathrm{Da}$ & $30.6 \pm 1.1 \mathrm{Bb}$ & $51.7 \pm 1.6 \mathrm{Aa}$ & $2.6 \pm 0.3 \mathrm{Da}$ \\
$\mathrm{B}$ & $11.4 \pm 0.4 \mathrm{Ca}$ & $3.8 \pm 0.6 \mathrm{Da}$ & $31.4 \pm 1.3 \mathrm{Bab}$ & $50.5 \pm 0.8 \mathrm{Aab}$ & $3.0 \pm 0.5 \mathrm{Da}$ \\
$\mathrm{C}$ & $11.3 \pm 0.1 \mathrm{Ca}$ & $4.1 \pm 0.2 \mathrm{Da}$ & $32.8 \pm 0.3 \mathrm{Ba}$ & $48.9 \pm 0.3 \mathrm{Ab}$ & $2.9 \pm 0.1 \mathrm{Da}$ \\
\hline \multicolumn{5}{c}{ Olive oil } \\
\hline $\mathrm{D}$ & $10.7 \pm 0.6 \mathrm{Ba}$ & $3.5 \pm 0.1 \mathrm{Ca}$ & $75.2 \pm 1.8 \mathrm{Aa}$ & $6.1 \pm 1.3 \mathrm{BCbc}$ & $4.6 \pm 0.1 \mathrm{Ca}$ \\
$\mathrm{E}$ & $12.1 \pm 1.2 \mathrm{Ba}$ & $2.8 \pm 0.2 \mathrm{Ca}$ & $69.3 \pm 5.7 \mathrm{Ab}$ & $11.4 \pm 6.8 \mathrm{Bb}$ & $4.5 \pm 0.4 \mathrm{Ca}$ \\
$\mathrm{F}$ & $11.1 \pm 0.7 \mathrm{Ba}$ & $3.7 \pm 0.3 \mathrm{Ca}$ & $75.2 \pm 1.6 \mathrm{Aa}$ & $5.4 \pm 0.9 \mathrm{BCc}$ & $4.6 \pm 0.2 \mathrm{Ca}$ \\
$\mathrm{G}$ & $11.3 \pm 0.2 \mathrm{Ca}$ & $3.9 \pm 0.2 \mathrm{Da}$ & $31.8 \pm 0.2 \mathrm{Bc}$ & $50.2 \pm 0.4 \mathrm{Aa}$ & $2.8 \pm 0.3 \mathrm{Da}$ \\
$\mathrm{H}$ & $11.1 \pm 0.2 \mathrm{Ca}$ & $3.8 \pm 0.2 \mathrm{Da}$ & $32.6 \pm 0.7 \mathrm{Bc}$ & $49.5 \pm 1.0 \mathrm{Aa}$ & $3.0 \pm 0.2 \mathrm{Da}$ \\
$\mathrm{I}$ & $11.3 \pm 0.1 \mathrm{Ca}$ & $3.7 \pm 0.2 \mathrm{Da}$ & $34.5 \pm 1.7 \mathrm{Bc}$ & $47.4 \pm 1.6 \mathrm{Aa}$ & $3.1 \pm 0.3 \mathrm{Da}$ \\
\hline
\end{tabular}

Data are means \pm standard deviation $(n=3)$. Different letters present significant difference by the Tukey test $(p<0.05)$. Different upper case letters represent significant difference between the fatty acids within the same trademark. Different lowercase letters represent significant difference of the same fatty acid between the marks of the same matrix. $(-)=$ not detected.

The fatty acids C16:0, C18:0, C18:1, C18:2, and C18:3 were identified in the samples of soybean oil (A, B and C). Higher amounts of C18:2 were identified (48.9\% to $51.7 \%)$, followed by C18:1, which 
presented an average of $31.6 \%$ for all samples analyzed. Thus, the fatty acid profile of these samples was predominantly unsaturated, corresponding to approximately $83 \%$ of the oil.

The samples of soybean oil presented significant differences when compared to C18:1 acid, with the marks B (31.4\%) and C (32.8\%) presenting a higher percentage of this acid, and the brands A (51.7\%) and B (50.5\%) presenting higher content of C18:2. However, the other acids did not shown any difference when compared to the trademarks. Thus, the profile of fatty acids in this study was similar to that reported in the scientific literature for soybean oils (Dhakal et al. 2009b); in addition, the results are according to the limits established by the Brazilian legislation that regulates their commercialization (MAPA, 2006).

The olive oil brands analyzed in this study showed qualitative and quantitative differences in their lipid profiles (Table 6). C18:1 presented a significant difference when compared to the other fatty acids, being the majority in samples D (75.2\%) and F (75.2\%). However, for samples G, H and I, C18:2 was predominant with $50.2 \%, 49.5 \%$ and $47.4 \%$, respectively. In general, olive oil samples also showed a predominantly unsaturated profile, as well as in soybean oils (Table 6).

The results for the olive oil brands tested in this study demonstrated significant differences for the predominant fatty acids - C18:1 (31.8\% to $75.2 \%)$ and C18:2 (5.4\% to 50.2\%). Thus, according to the Brazilian legislation (MAPA, 2012) and other studies (Gómez-Coca et al. 2016), only D, E and F samples have percentages which are in accordance with the olive oil classification. The other samples can't receive the same denomination, once the characterization of the lipid profile mischaracterized them as olive oil samples, suggesting their adulteration (MAPA, 2012; Wirasnita et al., 2013).

It is necessary to emphasize that the fatty acids profile non-compliant with the legislation suggests an indication of fraud. Additional physical-chemical analyzes are required to confirm the adulteration, including: acidity index, peroxide index, density, color and others (MAPA, 2012, 2006). Acidity and concentration of the fatty acids are available for the consumers once they are provided on the labels of these products. Thus, the proposed method aims to assist in the quantification of fatty acids in a comparative way with the labeling of the products, guaranteeing reliable results. Therefore, in order to demonstrate its applicability, fatty acid concentrations were calculated (Table 7).

Table 7 - Concentration of fatty acids from samples of commercial oils. Concentration in $\mathrm{mg} \cdot \mathrm{mL}^{-1}$

\begin{tabular}{lccccc}
\hline \multirow{2}{*}{ Samples } & \multicolumn{5}{c}{ Concentration } \\
\cline { 2 - 6 } & C16:0 & C18:0 & C18:1 & C18:2 & C18:3 \\
\hline A & $2.15 \pm 0.45 \mathrm{Ca}$ & $0.70 \pm 0.15 \mathrm{Ca}$ & $5.87 \pm 1.45 \mathrm{Ba}$ & $9.83 \pm 1.97 \mathrm{Aa}$ & $0.49 \pm 0.14 \mathrm{Ca}$ \\
$\mathrm{B}$ & $2.30 \pm 0.31 \mathrm{Ca}$ & $0.73 \pm 0.01 \mathrm{Ca}$ & $6.39 \pm 1.19 \mathrm{Ba}$ & $10.24 \pm 1.69 \mathrm{Aa}$ & $0.59 \pm 0.16 \mathrm{Ca}$ \\
$\mathrm{C}$ & $2.47 \pm 0.10 \mathrm{Ca}$ & $0.86 \pm 0.04 \mathrm{Ca}$ & $7.19 \pm 0.32 \mathrm{Ba}$ & $10.71 \pm 0.37 \mathrm{Aa}$ & $0.73 \pm 0.01 \mathrm{Ca}$ \\
\hline \multicolumn{5}{c}{ Olive oil } \\
\hline $\mathrm{D}$ & $1.89 \pm 0.13 \mathrm{Ba}$ & $0.62 \pm 0.05 \mathrm{Ba}$ & $13.59 \pm 0.95 \mathrm{Aa}$ & $0.90 \pm 0.25 \mathrm{Bb}$ & $0.77 \pm 0.06 \mathrm{Ba}$ \\
$\mathrm{E}$ & $2.41 \pm 0.28 \mathrm{Ba}$ & $0.55 \pm 0.08 \mathrm{Ca}$ & $14.00 \pm 0.61 \mathrm{Aa}$ & $2.19 \pm 1.58 \mathrm{BCb}$ & $0.83 \pm 0.06 \mathrm{BCa}$ \\
F & $2.22 \pm 0.25 \mathrm{Ba}$ & $0.73 \pm 0.11 \mathrm{Ba}$ & $15.28 \pm 1.07 \mathrm{Aa}$ & $0.91 \pm 0.24 \mathrm{Bb}$ & $0.86 \pm 0.08 \mathrm{Ba}$ \\
$\mathrm{G}$ & $2.31 \pm 0.24 \mathrm{Ca}$ & $0.78 \pm 0.11 \mathrm{Ca}$ & $6.51 \pm 0.56 \mathrm{Bb}$ & $10.26 \pm 0.85 \mathrm{Aa}$ & $0.54 \pm 0.08 \mathrm{Ca}$ \\
$\mathrm{H}$ & $2.36 \pm 0.09 \mathrm{Ca}$ & $0.79 \pm 0.02 \mathrm{Ca}$ & $6.95 \pm 0.23 \mathrm{Bb}$ & $10.55 \pm 0.71 \mathrm{Aa}$ & $0.61 \pm 0.04 \mathrm{Ca}$ \\
$\mathrm{I}$ & $2.36 \pm 0.29 \mathrm{Ca}$ & $0.75 \pm 0.12 \mathrm{Ca}$ & $7.24 \pm 1.04 \mathrm{Bb}$ & $9.89 \pm 1.21 \mathrm{Aa}$ & $0.61 \pm 0.03 \mathrm{Ca}$ \\
\hline
\end{tabular}

Data are means \pm standard deviation $(n=3)$. Different letters present significant difference by the Tukey test $(p<0.05)$. Different upper case letters represent significant difference between the fatty acids within the same trademark. Different lowercase letters represent significant difference of the same fatty acid between the brands of the same matrix. $(-)=$ not detected.

The concentration of the fatty acids demonstrated similarity to the lipid profile for all of the analysed commercial samples, excepting some variations in C18:1 and C18:2 acids (Table 6 and 7). The C18:2 acid showed higher concentration for samples A, B, C, G, H and I, with contents ranging from $9.83 \mathrm{mg} \cdot \mathrm{mL}^{-1}$ (sample A) to $10.71 \mathrm{mg} \cdot \mathrm{mL}^{-1}$ (sample C). It is possible to observe that olive oil samples $\mathrm{G}$, 
$\mathrm{H}$ and I have a very similar lipid profile to that of soybean oil samples (A, B and C), reinforcing the suggestion of adulteration for soybean oil. However, samples D, E and F demonstrated the highest C18:1 concentrations with values ranging from $13.59 \mathrm{mg} \cdot \mathrm{mL}^{-1}$ (sample D) to $15.28 \mathrm{mg} \cdot \mathrm{mL}^{-1}$ (sample F), as expected for an authentic sample of olive oil (Piravi-Vanak et al. 2009; Jabeur et al. 2015; Jiang et al. 2015; Mendes et al. 2015).

The Brazilian legislation regulates the quantification of fatty acids for the evaluation of their authenticity by percentage; thus, the characterization of commercial oils could not be evaluated by concentration (MAPA, 2012, 2006). These information do not correspond to the nutritional ones contained in the labels of the products, which difficult the verification of the oils' veracity by consumers. Therefore, the proposed method becomes useful in the checking of oil samples with their labels informed by the manufacturer.

Finally, the equivalence of fatty acid information for both determinations, this is percentage and concentration, suggests that the proposed method is capable of quantifying vegetable fatty acids with precision and accuracy. The method can be used as an additional tool for the investigation of commercial vegetable oils adulterated, especially in what concerns the olive oil, since the scientific literature (Antoniassi et al. 1998; Aued-Pimentel et al. 2008) reports the inappropriate sale of the above mentioned oil adulterated with soybean, canola and sunflower oils in the Brazilian market.

Figure 1 - Chromatogram of a fatty acid methyl esters standard mixture, at the concentrations of 5.19, 23.50, 13.32, 1.46 and 1.90 mg.mL-1, respectively. 1- C16:0, 2- C18:2, 3- C18:1, 4- C18:3 e 5- C18:0

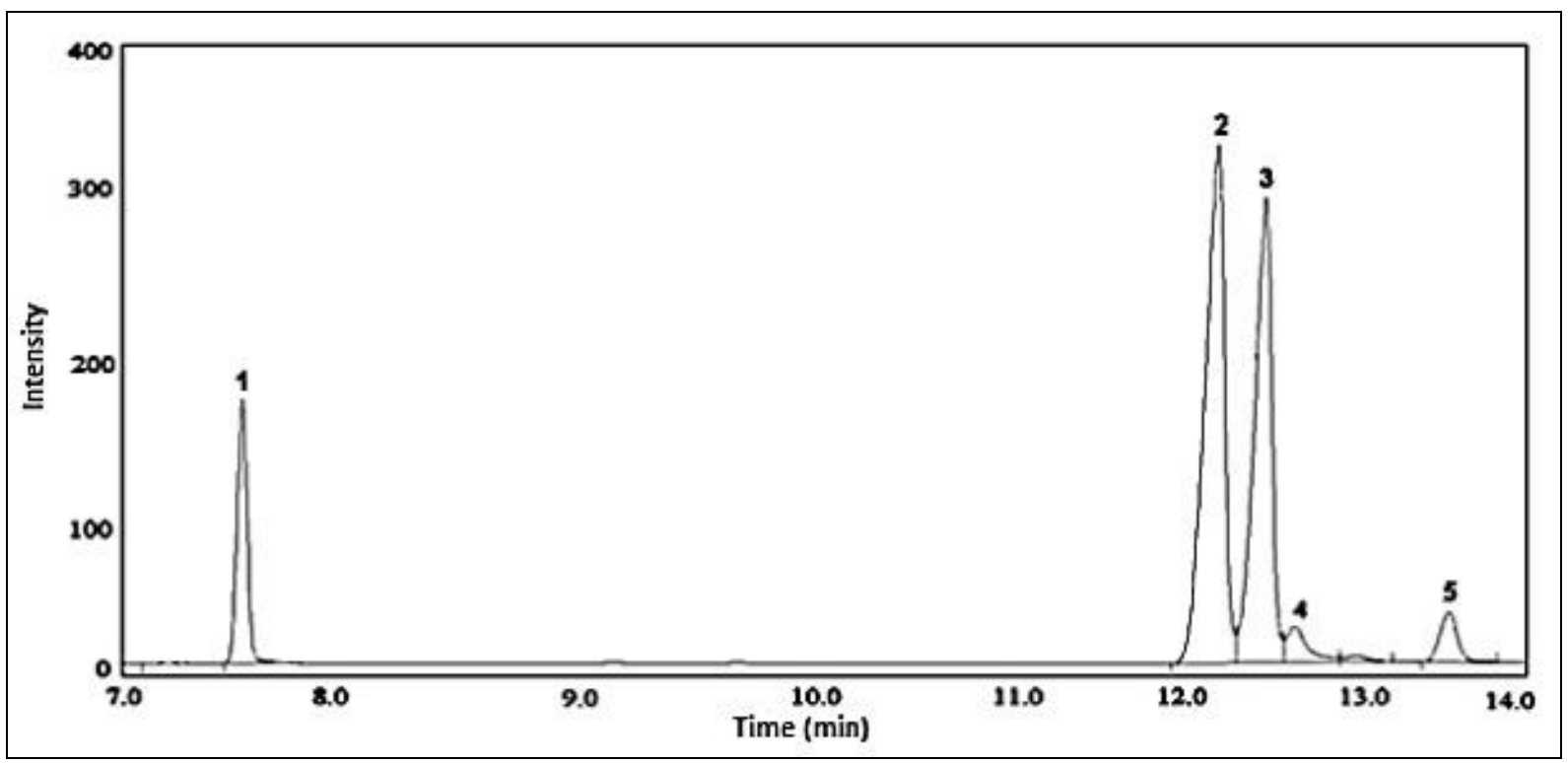

\section{Conclusion}

The basic transesterification method used for derivatization of fatty acids in commercial vegetable oils was efficient in the conversion for GC-FID analysis; in addition, the chromatographic method proved to be linear, precise and accurate in quantification. The proposed methodology is advantageous since it uses low toxicity and low cost solvents, associated to a rapid and efficient analysing time in the separation of analytes of similar nature.

This methodology showed statistically similar results when the lipid profile was quantified in terms of percentage and concentration. Due to the fact that Brazilian and international legislation for vegetable oils determines the presentation of fatty acids in terms of percentage, this information is desynchronized for consumers, since the labels of the marketed products only present the concentrations of the analytes. In this sense, synchronizing information about percentage and concentration is indispensable for the use of a reliable methodology to determine FAMEs. Therefore, the methodology 
proposed in this work has proved to be an efficient tool for investigating the adulteration of commercial vegetable oils.

\section{Acknowledgments}

Authors would like to acknowledge the agency in Brazil that have supported this research: National Council for Scientific and Technological Development (CNPq) and Northeast Centre of Strategic Technologies (CETENE).

\section{References}

ABNT - Associação Brasileira de Normas Técnicas (2005) NBR ISO/IEC 17025:2005, Requisitos gerais para competência de laboratórios de ensaio e calibração.

ANTONIASSI R, PEREIRN DA, SZPIZ RR, et al (1998) Evaluation of the identity and quality characteristics of olive oil samples. Brazilian J Food Technol 1:32-43.

ANVISA - Agência Nacional de Vigilância Sanitária (2017) Resolução da Diretoria colegiada RDC No 166:2017

AUED-PIMENTEL S, TAKEMOTO E, KUMAGAI EE, CANO CB (2008) Determinação da diferença entre o valor real e o teórico do triglicerídeo ecn 42 para a detecção de adulteração em azeites de oliva comercializados no Brasil. Quim Nova 31:31-34.

BARROS NETO B DE, PIMENTEL MF, ARAÚJO MCU (2002) Recomendações para calibração em química analítica - parte I. fundamentos e calibração com um componente (calibração univariada). Quim Nova 25:856-865

BRANDT M, MOSS J, FERGUSON M (2009) The 2006-2007 Food Label and Package Survey (FLAPS): Nutrition labeling, trans fat labeling. J Food Compos Anal 22:74-77.

BRAVI E, MARCONI O, SILEONI V, PERRETTI G (2017) Determination of free fatty acids in beer. Food Chem 215:341-346.

BRITO N (2003) Validação de métodos analíticos: Estratégia e discussão. Pestic Rev Ecotoxicologia e Meio Ambient 13:129-146.

DELMONTE P, FARDIN-KIA AR, HU Q, RADER J (2009) Review of methods for preparation and gas chromatographic separation of trans and cis reference fatty acids. J AOAC Int 92:1310-1326

DHAKAL KH, JEONG Y-S, LEE J-D, et al (2009a) Fatty acid composition in each structural part of soybean seed and sprout. J Crop Sci Biotechnol 12:97-101.

DHAKAL KH, JEONG Y, LEE J, et al (2009b) Fatty Acid Composition in each Structural Part of Soybean Seed and Sprout. 2009:97-101.

DUBOIS V, BRETON S, LINDER M, et al (2007) Fatty acid profiles of 80 vegetable oils with regard to their nutritional potential. Eur J Lipid Sci Technol 109:710-732.

FARIA RCM, REZENDE MJC, REZENDE CM (2007) Desenvolvimento e validação de metodologia de análise de misturas biodiesel:diesel utilizando cromatografia gasosa-espectrometria de massas. Quim Nova 30:1900-1905. 
GODSWILL N-N, FRANK N-EG, EDSON M-YJ, ET al (2014) GC-FID Method Development and Validation Parameters for Analysis of Palm Oil (Elaeis guineensis Jacq.) Fatty Acids Composition. Res Plant Sci 2:53-66.

GÓMEZ-COCA RB, FERNANDES GD, PÉREZ-CAMINO M DEL C, MOREDA W (2016) Fatty acid ethyl esters (FAEE) in extra virgin olive oil: A case study of a quality parameter. LWT - Food Sci Technol 66:378-383.

GRUBBS FE, BECK G (2017) American Society for Quality Extension of Sample Sizes and Percentage Points for Significance Tests of Outlying Observations Linked references are available on JSTOR for this article : Extension of Sample Sizes and Percentage Points for Significance Tests. 14:847-854

INMETRO - Instituto nacional de metrologia normalização e qualidade industrial (2010) Orientação Sobre Validação De Métodos Analíticos - DOQ-CGCRE-008.

JABEUR H, ZRIBI A, ABDELHEDI R, BOUAZIZ M (2015) Effect of olive storage conditions on Chemlali olive oil quality and the effective role of fatty acids alkyl esters in checking olive oils authenticity. Food Chem 169:289-296.

JABEUR H, ZRIBI A, BOUAZIZ M (2016) Extra-Virgin Olive Oil and Cheap Vegetable Oils: Distinction and Detection of Adulteration as Determined by GC and Chemometrics. Food Anal Methods 9:712-723.

JIANG L, ZHENG H, LU H (2015) Application of UV spectrometry and chemometric models for detecting olive oil-vegetable oil blends adulteration. J Food Sci Technol 52:479-485.

MAPA - Ministério da Agricultura Pecuária e Abastecimento (2012) Instrução normativa No 1 Regulamento técnico do azeite de oliva e do óleo de bagaço de oliva.

MAPA - Ministério da Agricultura Pecuária e Abastecimento (2006) Instrução normativa No 49 Regulamento técnico de identidade e qualidade dos óleos vegetais refinados, a amostragem, os procedimentos complementares e o roteiro de classificação de óleos vegetais refinados.

MENDES TO, DA ROCHA RA, Porto BLS, et al (2015) Quantification of Extra-virgin Olive Oil Adulteration with Soybean Oil: a Comparative Study of NIR, MIR, and Raman Spectroscopy Associated with Chemometric Approaches. Food Anal Methods 8:2339-2346.

NUNES CA, SOUZA VR DE, CORREAA SC, et al (2013) Heating on the volatile composition and sensory aspects on extra-virgin olive oil. Cienc e Agrotecnologia 37:566-572.

OMAR TA, SALIMON J (2013) Validation and application of a gas chromatographic method for determining fatty acids and trans fats in some bakery products. J Taibah Univ Sci 7:56-63.

PETROVIĆ M, KEZIĆ N, BOLANČA V (2010) Optimization of the GC method for routine analysis of the fatty acid profile in several food samples. Food Chem 122:285-291.

PIRAVI-VANAK Z, GHAVAMI M, EZZATPANAH H, et al (2009) Evaluation of Authenticity of Iranian Olive Oil by Fatty Acid and Triacylglycerol Profiles. JAOCS, J Am Oil Chem Soc 86:827-833.

RIBANI M, GRESPAN BOTTOLI CB, COLLINS CH, et al (2004) Validação em métodos cromatográficos e eletroforéticos. Quim Nova 27:771-780. 
SALIMON J, OMAR TA, SALIH N (2017) An accurate and reliable method for identification and quantification of fatty acids and trans fatty acids in food fats samples using gas chromatography. Arab J Chem 10:S1875-S1882.

SEPPÄNEN-LAAKSO T, LAAKSO I, HILTUNEN R (2002) Analysis of fatty acids by gas chromatography, and its relevance to research on health and nutrition. Anal Chim Acta 465:39-62.

SIMIONATO JI, GARCIA JC, DOS SANTOS GT, et al (2010) Validation of the determination of fatty acids in milk by gas chromatography. J Braz Chem Soc 21:520-524.

SIQUEIRA APS, CASTRO CFDS, SILVEIRA EV, LOURENÇO MF de C (2016) Chemical quality of Baru almond (Dipteryx alata oil). Ciência Rural 46:1865-1867.

SLEMR J, SLEMR F, D'SOUZA H, PARTRIDGE R (2004) Study of the relative response factors of various gas chromatograph-flame ionisation detector systems for measurement of C2-C9hydrocarbons in air. J Chromatogr A 1061:75-84.

SUN X, LIN W, LI X, et al (2015) Analytical Methods Detection and quanti fi cation of extra virgin olive oil adulteration with edible oils by FT-IR spectroscopy and chemometrics. Anal Methods 7:3939-3945.

TIWARI G, TIWARI R (2010) Bioanalytical method validation: An updated review. Pharm Methods 1:25.

WIRASNITA R, HADIBARATA T, NOVELINA YM, et al (2013) A modified methylation method to determine fatty acid content by gas chromatography. Bull Korean Chem Soc 34:3239-3242.

YURCHENKO S, SATS A, POIKALAINEN V, KARUS A (2016) Method for determination of fatty acids in bovine colostrum using GC-FID. Food Chem 212:117-122. 